\title{
Evaluation of an on-line coupled continuous flow liquid membrane extraction and precolumn system as trace enrichment technique by liquid chromatographic determination of bisphenol A
}

\author{
Jing-fu Liu ${ }^{\text {a }}$, Xia Liang ${ }^{\text {a,b }}$, Gui-bin Jiang ${ }^{\text {a,*, Ya-qi Cai }}{ }^{\text {a }}$, Qing-xiang Zhou ${ }^{\text {a,b }}$, \\ Guo-guang Liu ${ }^{\mathrm{b}}$ \\ ${ }^{a}$ Key Laboratory of Environmental Chemistry and Ecotoxicology, Research Center for Eco-Environmental Sciences, Chinese Academy of \\ Sciences, P.O. Box 2871, Beijing 100085, China \\ ${ }^{\mathrm{b}}$ Key Laboratory of Environmental Science and Engineering, College of Environmental Sciences and Chemistry, Henan Normal \\ University, Xinxiang 453002, Henan, China
}

Received 2 December 2002; received in revised form 3 March 2003; accepted 4 March 2003

\begin{abstract}
An on-line coupled continuous flow liquid membrane extraction (CFLME) and $\mathrm{C}_{18}$ precolumn system was developed for sample preconcentration in liquid chromatography determination. After preconcentration by CFLME, which is based on the combination of continuous flow liquid-liquid extraction and supported liquid membrane, bisphenol A (BPA) was enriched in $960 \mu \mathrm{l}$ of $1 \mathrm{~mol}^{-1} \mathrm{NaOH}$ used as acceptor. This acceptor was on-line neutralized and transported onto the $\mathrm{C}_{18}$ precolumn where analytes were absorbed and focused. Then the focused analytes were injected onto a $\mathrm{C}_{18}$ analytical column for separation and detected at $220 \mathrm{~nm}$ with a diode array detector. CFLME related parameters such as flow rates, $\mathrm{pH}$ of donor and acceptor, and enrichment time were optimized. The proposed method presents a detection limit of $0.03 \mu \mathrm{g} 1^{-1}(S / N=3)$ when $60 \mathrm{ml}$ samples was enriched with an enrichment time of $30 \mathrm{~min}$. Compared with $\mathrm{C}_{18}$ based column-switching procedure, this proposed procedure presents similar sample throughput and lower detection limits. The proposed method was successfully applied to determine BPA in tap water, river water, and municipal sewage effluent samples.
\end{abstract}

(C) 2003 Elsevier B.V. All rights reserved.

Keywords: On-line enrichment; Continuous flow liquid membrane extraction; Precolumn; Bisphenol A; Water samples

\section{Introduction}

Trace-enrichment, an indispensable step in many analytical procedures, is usually performed

* Corresponding author. Fax: +86-10-6292-3563.

E-mail address: gbjiang@mail.rcees.ac.cn (G.-b. Jiang). by liquid-liquid extraction or solid phase extraction (SPE). Although SPE is a relatively more 
recent and popular technique, further study of alternative sample pretreatment procedure is of interest and some sample preconcentration technique such as solid-phase microextraction, various micro-liquid-liquid extraction and membrane based extraction techniques were reported.

In our previous study [1-3], continuous flow liquid membrane extraction (CFLME) was developed for automatic sample preconcentration. The new aqueous-organic-aqueous extraction technique is based on the combination of continuous flow liquid-liquid extraction and supported liquid membrane (SLM) extraction. In this procedure, analyte was first extracted into the organic phase as a neutral molecule in the continuous flow liquid-liquid extraction step, and then transported into the organic liquid membrane that formed on the surface of the micro porous membrane of the SLM equipment. Finally, it passed through the liquid membrane and was trapped in its ionic form by the acceptor.

The objective of this present study is to develop an on-line coupled CFLME- $\mathrm{C}_{18}$ precolumn traceenrichment system and evaluate its applicability in real sample analysis by using bisphenol A (BPA or 4,4'-isopropylidenediphenol) as a test compound. With this proposed trace-enrichment system, BPA was firstly enriched in $960 \mu \mathrm{l}$ of $1 \mathrm{~mol} 1^{-1} \mathrm{NaOH}$ acceptor, and then on-line neutralized and transported onto the $\mathrm{C}_{18}$ precolumn where analytes were absorbed and focused. Finally, the focused analytes were injected onto a $\mathrm{C}_{18}$ analytical column for separation and detected at $220 \mathrm{~nm}$ with a diode array detector.

As BPA is reported to possess estrogenic activities, a great deal of attention has been recently focused on its environmental impacts and ecotoxicological effects. For trace levels BPA related studies, a sensitive and selective analytical methods for its determination in environmental and food matrices is imperative.

So far, the analysis of BPA has been accomplished mainly by chromatographic methods, and a few analytical methods are available for the determination of BPA in environmental samples. Peltonen et al. [4] described a liquid chromatographic method with electrochemical detection for the determination BPA in air. Gas chromatography-mass spectrometry [5] and liquid chromatography-mass spectrometry [6] methods were reported for the determination of BPA in water samples. Later, Lee et al. [7] developed a gas chromatography/mass spectrometry method for the analysis of BPA in sewage effluent and sludge. More recently, an high resolution gas chromatography-(negative chemical ionization)-mass spectrometry method [8] was developed for the determination of BPA in surface and drinking water at $\mathrm{pg}^{-1}$ level. Generally speaking, samples must be pretreated before determining by these methods. The sample pretreatment procedures applied included Soxhlet extraction [9], liquidliquid extraction [5,10], SPE [6-8], microwaveassisted solvent extraction [11], supercritical fluid extraction [7], and solid-phase microextraction [12]. Among them, the SPE procedure was the most widely used one.

\section{Experimental}

\subsection{Reagents and chemicals}

Bisphenol A (BPA, 97\%) was purchased from Acros Organics (NJ, USA). Standard stock solution was prepared by dissolving $20 \mathrm{mg}$ of standard in $100 \mathrm{ml}$ of water and stored at $4{ }^{\circ} \mathrm{C}$. Working solutions were obtained daily by appropriate diluting the stock solutions with water.

All other chemicals were purchased from Beijing Chemicals Corporation and were analytical grade or better. De-ionized water was used throughout.

\subsection{Apparatus and materials}

Fig. 1 shows the schematic diagram of the CFLME-C $_{18}$ precolumn-HPLC system. The CFLME part consists of a few pumps and valves and a SLM device. The custom-made SLM device shown in Fig. 1 consisted of PTFE block (PB), PTFE membrane (PM) and aluminum backer (AB). The PTFE block was machined from two blocks of Teflon by cutting two Archimedes' spiral grooves (SC) on the opposite faces of the two blocks. The grooves have identical dimensions of $0.3 \mathrm{~mm}$ deep, $2.0 \mathrm{~mm}$ wide and $160 \mathrm{~cm}$ long. The 


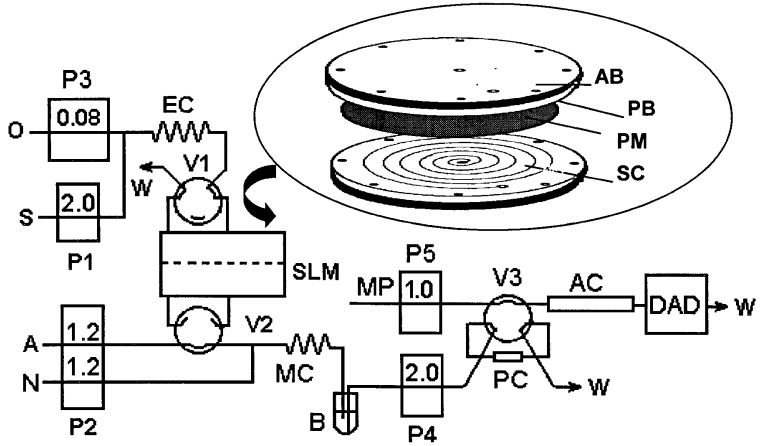

Fig. 1. Schematic diagram of the experimental setup. The flow rates of each solution were shown as $\mathrm{ml} \mathrm{min}^{-1}$ in the symbols of pumps. See text for more details. P1, P2, P3, P4, P5, pumps; V1, V2, V3, valves; MC, mixing coils; EC, extraction coil; SLM, supported liquid membrane device; $\mathrm{B}, 5 \mathrm{ml}$ test tube; $\mathrm{PC}, \mathrm{C}_{18}$ precolumn; AC, analytical column; DAD, detector; $\mathrm{S}$, sample; $\mathrm{O}$, organic solvent (dichloromethane); A, acceptor $\left(1.0 \mathrm{~mol}^{-1}\right.$ $\mathrm{NaOH}) ; \mathrm{N}$, neutralization reagent $\left(0.6 \mathrm{~mol} \mathrm{l} \mathrm{H}^{-1} \mathrm{H}_{2} \mathrm{SO}_{4}\right)$; MP, mobile phase; $\mathrm{W}$, waste; $\mathrm{AB}$, aluminum backer; $\mathrm{PB}$, PTFE block; PM, PTFE membrane; SC, spiral channel.

membrane was clamped tightly and evenly between the planar surfaces of the blocks by eight screws. Thus, two channels (the acceptor channel and the donor channel) with the same volume of $960 \mu \mathrm{l}$ were obtained. To make the device more rigid, each PTFE block was backed by an aluminum block. The membrane used as support of the organic liquid is Fluoropore FG PTFE membrane (average pore size $0.2 \mu \mathrm{m}$, porosity 0.7 ; Millipore Corp., Bedford, MA, USA).

The liquid chromatographic separations system was performed with LC-VP (Shimadzu, Japan) series products that consisted of an SCL-10Avp system controller, a LC-10ATvp pump (P5), and an SPD-M10Avp diode array detector (DAD) which was set at $220 \mathrm{~nm}$ wavelength as detector. Data acquisition and process were accomplished with a Class-VP Workstation (Shimadzu, Japan). A 7725 injector (Rheodyne, USA) whose sampling loop was replaced by a $\mathrm{C}_{18}$ precolumn $(16 \mathrm{~mm} \times$ $4.0 \mathrm{~mm}$ I.D., Three Dimension Chromatography Co., Tianjin, China) was employed to inject the focused samples. The analytical column was a 150 $\mathrm{mm} \times 4.6 \mathrm{~mm}$ I.D. $\mathrm{C}_{18}$ column (Diamonsil ${ }^{\mathrm{TM}}$, Dickma Co., China, $5 \mu \mathrm{m}$ particles).

\subsection{Procedure}

\subsubsection{CFLME- $C_{18}$ precolumn preconcentration procedure}

The whole CFLME- $\mathrm{C}_{18}$ precolumn preconcentration system is shown in Fig. 1. The CFLME step is conducted as described in detail elsewhere [2]. Briefly, sample solution (S) introduced into the system by a piston pumps (P1, MiniPump, Laboratory Date Control, Division of Milton Roy Company) was segmented by organic solvent (O) delivered by a microinfusion pump (P3, Model WZ-50G, Medical Instrument Factory of Zhejiang University, China). Extraction of BPA into the organic phase takes place in the extraction coil (EC). When the segments of sample and organic phase passed through the donor channel of the SLM device, the organic phase soaked up PTFE membrane and thus formed the "supported liquid membrane", and BPA was extracted into the liquid membrane and back-extracted into the acceptor, i.e. BPA passed through the liquid membrane and was finally trapped by the acceptor.

After then, a peristaltic pump (P2) was activated to introduce acceptor (A) and another stream of neutralization reagent $\left(\mathrm{N}, 0.6 \mathrm{~mol}^{-1} \mathrm{H}_{2} \mathrm{SO}_{4}\right)$ into the mixing coil (MC). The acceptor was acidified to about $\mathrm{pH} \mathrm{3-5}$ in $\mathrm{MC}$ and was delivered into a 5-ml test tube (B). At the same time, P4 was activated to transport the mixture in the test tube onto the $\mathrm{C}_{18}$ precolumn (PC) where analytes were focused. Ninety seconds later, P2 stopped automatically, and V1 and V2 were manually switched to the injection position and bypass position, respectively. Then, into the test tube was added 3

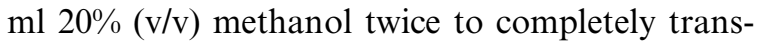
port the analytes onto the precolumn and at the same time wash away the salt in the precolumn. The final step is the injection step. When the P4 stopped, V3 was switched to the injection position to introduce the analytes, focused on the precolumn, onto the analytical column for separation and finally detected by the DAD detector.

While the analytes separating on the analytical column, the next enrichment can be processed simultaneously. To avoid memory effects, the continuous flow liquid-liquid extraction manifold 
and the donor channel of the SLM device were washed 1-2 min by using water as sample while the acceptor channel was washed with acceptor for $1 \mathrm{~min}$ before the next enrichment. The precolumn was also washed with $2 \mathrm{ml}$ of methanol and water in sequence to avoid memory effects.

\subsubsection{Column-switching procedure}

In this procedure, the system setup is the same as that shown in Fig. 1 except that the CFLME device was not used. Samples were transported directly onto the $\mathrm{C}_{18}$ precolumn with the MiniPump (P4) by switching V3 to the loading position. Then, V3 was switched to the injection position to introduce the analytes, adsorbed on the precolumn, onto the analytical column for HPLC analysis.

\subsubsection{HPLC analysis}

With a $\mathrm{C}_{18}$ analytical column and using a mixture of acetonitrile and water $(45+55, \mathrm{v}+\mathrm{v})$ delivered at a flow rate of $1.0 \mathrm{ml} \mathrm{min}{ }^{-1}$ as mobile phase, BPA was separated within $10 \mathrm{~min}$.

\subsection{Sample collection}

Tap water was collected from laboratory about 5 min after flow in order to eliminate the sediment and gas pockets, and $0.1 \% \mathrm{Na}_{2} \mathrm{~S}_{2} \mathrm{O}_{3}$ was added to eliminate hypochlorite before spiking BPA; river water was collected from Yongding River in the suburb of Beijing. Municipal sewage effluent was collected at Gaobeidian sewage treatment works in the east part of Beijing. Before enrichment, tap water and river water were filtrated with $0.45 \mu \mathrm{m}$ micropore membrane and municipal sewage effluent was filtrated with $0.2 \mu \mathrm{m}$ micropore membrane.

\section{Results and discussion}

\subsection{Effect of CFLME related parameters}

In our previous work [2], the influence of some parameters for CFLME of BPA were investigated using a SLM device with a donor and acceptor channel dimension of $2 \mathrm{~mm}$ wide, $0.5 \mathrm{~mm}$ deep and $50 \mathrm{~mm}$ length. In this present work, however, as the donor and acceptor channel of the SLM device was much shallower and longer $(2 \times 0.3 \times$ $1600 \mathrm{~mm}$ ) than that used in our previous work, it is necessary to re-optimize some CFLME related parameters.

Experiments show that the extraction coil length has no significant influence on the peak area. Obviously this is because the donor and the acceptor channel of the present SLM device is long enough for analytes to be completely extracted into the organic phase in the donor channel and an extra long extraction coil is not necessary. If the SLM channel is short as in our previous study, however, prior extract the analytes into the organic phase by using a long extraction coil is helpful for the following SLM procedure. A $60 \mathrm{~cm}$ long extraction coil was adopted in the following studies.

The flow rate of dichloromethane has no significant influence on the peak area in the range $3.0-7.0 \mathrm{ml} \mathrm{h}^{-1}$. This probably is because when the donor and acceptor channel is long enough, analytes can be completely extracted into the organic phase and back extracted into the acceptor, and the extraction recovery is independent of the concentration in the organic phase in the donor. Though low flow rate is helpful for reducing the consumption of the toxic dichloromethane, a flow rate of $4.8 \mathrm{ml} \mathrm{h}^{-1}$ was adopted in this study as lower flow rate resulted in unstable flow system, which resulted from the relatively low pressure the microinfusion pump could provide.

The donor $\mathrm{pH}$ was optimized in the range of $\mathrm{pH}$ $3.0-7.0$ by adding appropriate $\mathrm{KH}_{2} \mathrm{PO}_{4} / \mathrm{NaOH}$ or $\mathrm{HOAc} / \mathrm{NaOAc}$ buffer solution to adjust sample

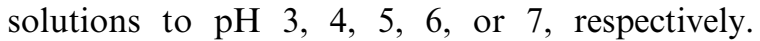
Results indicated that peak area keeps unchanged in the range of $\mathrm{pH} 3.0-4.0$, and then decreased with the increasing of $\mathrm{pH}$. Therefore, samples were adjusted to $\mathrm{pH} 3-4$ just before enriched by adding $6 \mathrm{~mol} 1^{-1} \mathrm{HCl}$ into basic samples or $2 \mathrm{~mol} \mathrm{l}^{-1}$ $\mathrm{NaOH}$ into acid samples.

Alkaline acceptor should be used to trap BPA in the acceptor stream. Using standard BPA solution, the $\mathrm{pH}$ of acceptor was optimized and results demonstrated that the highest peak was obtained at above $\mathrm{pH} 12.0$ [2]. When real samples were 
enriched, however, interferants with the same acid-base characteristics as the analytes could be co-extracted into the acceptor, which resulted in the decreasing of acceptor $\mathrm{pH}$ and thus the low recovery of analytes if the capacity of buffer is not large enough. Knutsson et al. [13] observed this phenomenon when they enriched chlorinated phenols in natural water by SLM. Our study [3] also demonstrated that interferents could be co-extracted and thus significantly reduced the recoveries of sulfonylurea herbicides in tap waters if the capacity of the acceptor buffer was not large enough. Therefore, $\mathrm{NaOH}$ was adopted as acceptor and its concentration was optimized in the range $0.1-1.5 \mathrm{~mol}^{-1}$ by enriching $1 \mu \mathrm{g}^{-1} \mathrm{BPA}$ spiked river water in this study. Experiment showed that there is no significant difference of peak area in the studied $\mathrm{NaOH}$ concentration range. Considering that relatively high concentration of $\mathrm{NaOH}$ can resist the influence of coextracted interferants in long-term enrichment and BPA is stable in $\mathrm{NaOH}$ solution, $1.0 \mathrm{~mol}$ $1^{-1} \mathrm{NaOH}$ was adopted as acceptor in the following studies.

The effect of salt was studied in the range 0 $20 \%(\mathrm{~m} / \mathrm{v}) \mathrm{NaCl}$ and results indicated that $\mathrm{NaCl}$ concentration had no significant influence on the peak area of BPA. This probably is because the donor and the acceptor channel of the present SLM device is long enough for analytes to be completely extracted into the organic phase in the donor channel, thus no salt effect was observed.

For long time enrichment, the acceptor $\mathrm{pH}$ in acceptor chamber might change and thus affect the enrichment efficiency. Thus, it is necessary to investigate the influence of enrichment time. The effect of enrichment time was studied by using 0.5 $\mu \mathrm{g} 1^{-1}$ BPA spiked river water and results indicated that the peak area of BPA increased linearly over the enrichment time range 30-180 min. This is because $1 \mathrm{~mol}^{-1} \mathrm{NaOH}$ was used as acceptor that can provide enough buffer capacity for long time enrichment in this study.

\subsection{Analytical performance date}

Extraction efficiency, a measure of the mass transfer rate through the membrane, is defined as the percentage of analyte extracted from the donor solution to the acceptor solution and was calculated from equation:

$\mathrm{E}=\mathrm{A}_{\mathrm{a}} / \mathrm{A}_{0}$

where $A_{a}$ was determined by enriching $60 \mathrm{ml}$ of 1 $\mu \mathrm{g} 1^{-1} \quad(60 \mathrm{ng})$ BPA standard solution with CFLME step at first, then transported neutralized acceptor in $3.0 \mathrm{ml}$ of solution, and then focused on the $\mathrm{C}_{18}$ precolumn and injected to determination. $\mathrm{A}_{0}$ was determined by direct focusing the same amount of BPA, $60 \mathrm{ng}$ prepared in $3.0 \mathrm{ml}$ solution, on the $\mathrm{C}_{18}$ precolumn. At the above-optimized conditions, the extraction efficiencies were determined to be $88 \pm 6 \%(n=3)$.

Some other characters of the proposed method such as linear ranges, regression equations, correlation coefficients, and detection limits were investigated by performing $30 \mathrm{~min}$ enrichment of standard solutions.

Regression equation and correlation coefficient, obtained by determining five BPA standards covering the linear range $0.1-50 \mu \mathrm{g}^{-1}$, were $A=90127 C+71451$ and $\mathrm{R}^{2}=0.9991$, respectively. The precision (R.S.D.) of the system measured by five repeated determination of 1.0 $\mu \mathrm{g} 1^{-1}$ BPA standard solution was $4.0 \%$. The calculated detection limit was $0.03 \mu \mathrm{g} 1^{-1}(S / N=$ $3)$. Lower detection limit should obviously be obtained if longer enrichment time was conducted. On the other hand, the enrichment time can be reduced to $10 \mathrm{~min}$ if high enrichment factor was not expected.

The PTFE membrane used in the SLM device has long-term stability. Experiments demonstrated that there is no significant difference between the peak areas of BPA obtained with a PTFE membrane used for 1 month and those obtained with a new membrane. The $\mathrm{C}_{18}$ precolumn used in this procedure is also very stable, no significant difference was observed after hundreds of usage during 2 months of experiment. This is because the sample was pretreated by the CFLME procedure, the sample matrix effect on the precolumn is very low. 


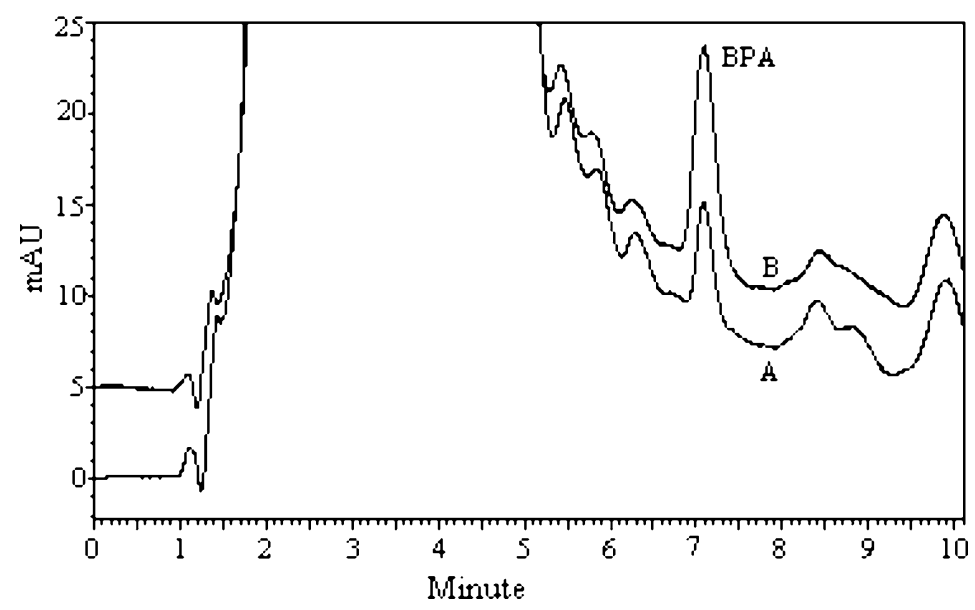

Fig. 3. Typical chromatograms obtained after enriching $120 \mathrm{ml}$ of municipal sewage effluent without (A) and with (B) spiking $0.5 \mu \mathrm{g}$ $1^{-1}$ BPA by the proposed procedure.

\subsection{Comparison with column-switching technique}

The proposed CFLME method was compared with column-switching (on-line SPE) procedure in respect of sensitivity and selectivity. $\mathrm{C}_{18}$ sorbent was used for comparison in this study as it is commonly used and is available in this laboratory. Fig. 2 showed the typical chromatograms obtained after enriching $120 \mathrm{ml}$ of $0.5 \mu \mathrm{g}^{-1}$ spiked river water by the proposed CFLME- $\mathrm{C}_{18}$ precolumn (A) and the column-switching (B) procedure, respectively. As can be seen, the proposed method obtained much higher BPA peak than the column- switching procedure. The lower BPA peak height in the column-switching procedure was resulted from the lower SPE recovery at low analyte concentration level. In the proposed CFLME-C $\mathrm{C}_{18}$ precolumn preconcentration procedure, analyte was preconcentrated by the CFLME step, and SPE was conducted at much higher analyte concentration level thus higher SPE recovery was obtained. The matrix peak was also different. In trace B very large matrix peak appeared in the retention time range $1.2-3.5 \mathrm{~min}$. In trace $\mathrm{A}$, however, the matrix peak appeared in the retention time range $1.2-3.5$ min was much smaller but

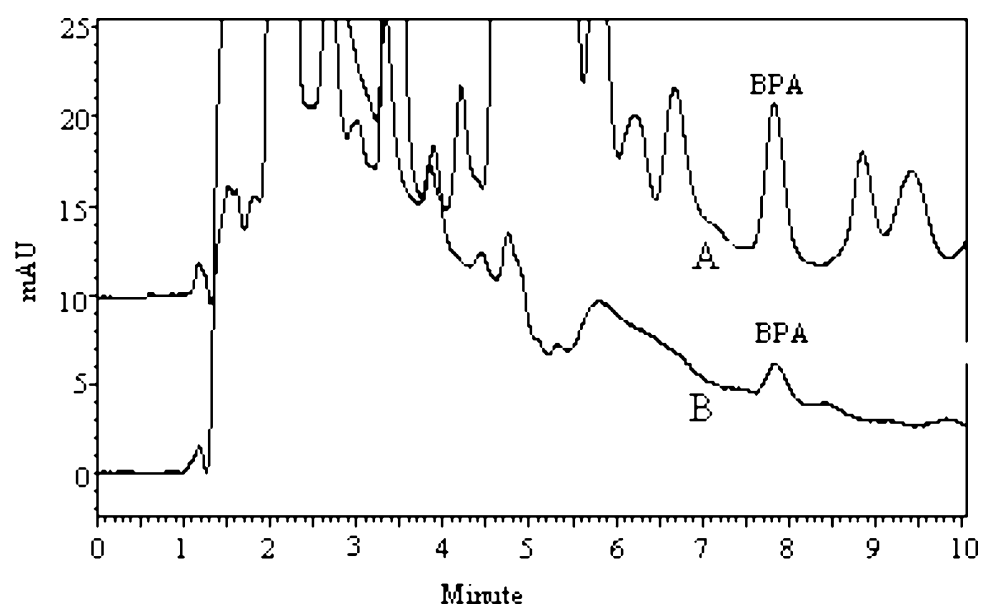

Fig. 2. Typical chromatograms obtained after enriching $120 \mathrm{ml}$ of $0.5 \mu \mathrm{g} 1^{-1}$ spiked river water by the proposed CFLME (A) and column-switching (B) technique. 
Table 1

Results and recoveries (mean $\pm \mathrm{s}, n=3$ ) of analysis of water samples spiked with $0.5 \mu \mathrm{g} 1^{-1}$ BPA by the proposed method

\begin{tabular}{|c|c|c|c|}
\hline \multirow[t]{2}{*}{ Sample } & \multicolumn{2}{|c|}{$\mathrm{BPA}\left(\mu \mathrm{g} \mathrm{1^{-1 }}\right)$} & \multirow[t]{2}{*}{ Recovery $(\%)$} \\
\hline & Added & Found & \\
\hline \multirow[t]{2}{*}{ Municipal sewage effluent } & 0 & 0.28 & \\
\hline & 0.5 & 0.78 & $99 \pm 7$ \\
\hline \multirow[t]{2}{*}{ River water 1} & 0 & $\mathrm{ND}^{\mathrm{a}}$ & \\
\hline & 0.5 & 0.38 & $76 \pm 3$ \\
\hline \multirow[t]{2}{*}{ River water 2} & 0 & $\mathrm{ND}^{\mathrm{a}}$ & \\
\hline & 0.5 & 0.58 & $116 \pm 12$ \\
\hline \multirow[t]{2}{*}{ Tap water } & 0 & $\mathrm{ND}^{\mathrm{a}}$ & \\
\hline & 0.5 & 0.48 & $95 \pm 10$ \\
\hline
\end{tabular}

a Not detected.

the matrix peaks around the BPA peak were relatively higher as interferants with similar acid-base characteristics as BPA were also more effectively enriched than in the column-switching procedure.

\subsection{Application to aqueous samples analysis}

In order to validate the proposed method, four aqueous samples including tap water, river water and municipal sewage effluent were analyzed and the recoveries were determined by spiking the samples with $0.5 \mu \mathrm{g}^{-1} \mathrm{BPA}$. Results shown in Table 1 indicates that the contents of BPA in the other three samples were all under the detection limits except that the municipal sewage effluent contains $0.28 \mu \mathrm{g}^{-1} \mathrm{BPA}$. The recoveries were in the range $76-116 \%$. Fig. 3 showed the typical chromatograms obtained after enriching $120 \mathrm{ml}$ of the municipal sewage effluent and the $0.5 \mu \mathrm{g} 1^{-1}$ spiked municipal sewage effluent by the proposed procedure.

\section{Conclusion}

Combining continuous flow liquid membrane extraction and $\mathrm{C}_{18}$ precolumn, a novel automatic procedure was developed and evaluated by analysis of BPA at low $\mu \mathrm{g}^{-1}$ levels in water samples. The CFLME- $\mathrm{C}_{18}$ precolumn procedure presents lower detection limits than $\mathrm{C}_{18}$ based columnswitching technique. The proposed CFLME procedure has long-term stability and similar sample pretreatment rate with column-switching technique.

\section{Acknowledgements}

This work was supported by the National Natural Science Foundation of China (20177026, 20137010) and the Chinese Academy of Sciences (KZCX2-414).

\section{References}

[1] J. Liu, J. Chao, G. Jiang, Anal. Chim. Acta 455 (2002) 93 101.

[2] J. Liu, J. Chao, M. Wen, G. Jiang, J. Sep. Sci. 24 (2001) 874-878.

[3] J. Chao, J. Liu, M. Wen, J. Liu, Y. Cai, G. Jiang, J. Chromatogr. A 955 (2002) 183-189.

[4] K. Peltonen, J. Pukkila, J. Chromatogr. 439 (1988) 375380.

[5] M. del Olmo, A. Gonzalez-Casado, N.A. Navas, J.L. Vilchez, Anal. Chim. Acta 346 (1997) 87-92.

[6] A. Motoyama, A. Suzuki, O. Shirota, R. Namba, Rapid Commun. Mass Spectrom. 13 (1999) 2204-2208.

[7] H. Lee, T.E. Peart, J. AOAC Int. 83 (2000) 290-297.

[8] H.M. Kuch, K. Ballschmiter, Environ. Sci. Technol. 35 (2001) 3201-3206.

[9] J.S. Khim, K. Kannan, D.L. Villeneuve, C.H. Koh, J.P. Giesy, Environ. Sci. Technol. 33 (1999) 4199-4205.

[10] P. Varelis, D. Balafas, J. Chromatogr. A 883 (2000) 163 170.

[11] S.N. Pedersen, C. Lindholst, J. Chromatogr. A 864 (1999) 17-24.

[12] J. Salafranca, R. Batlle, C. Nerin, J. Chromatogr. A 864 (1999) 137-144.

[13] M. Knutsson, L. Mathiasson, J.A. Jönsson, Chromatographia 42 (1996) 165. 